\title{
Correlação entre cobertura vacinal e notificações por sarampo no Distrito Federal
}

\author{
Correlation between immunization coverage and measles reports in the Federal District
}

\section{Correlación entre cobertura vacunal y notificaciones por sarampión en el Distrito Federal}

Ruan da Silva Barreto Ferreira ${ }^{1}$, Jefferson Robert Roque de Sousa ${ }^{1}$, Jéssica Larissa Pereira dos Santos $^{1}$, Sheila Maciel da Silva ${ }^{1}$, Alana Caroline da Silva Rosa ${ }^{1}$, Juliana Pires Rodrigues da Costa ${ }^{1}$, Johnata da Cruz Matos ${ }^{1-2 *}$.

\section{RESUMO}

Objetivo: correlacionar a cobertura vacinal com os números de notificação por sarampo no Distrito Federal, no período de 2008 a 2018. Método: trata-se de um estudo retrospectivo descritivo, com análise quantitativa, por meio de dados secundários, obtidos através dos sistemas de base de dados nacionais, do período de 2008 a 2018, sendo campo de estudo o Distrito Federal. Resultados: Na pesquisa realizada, evidenciou-se como resultados, a instabilidade dos valores da CV da Tríplice Viral na última década, com picos ora elevados, ora decaídos, e ao correlacionar os dados fornecidos pelos sistemas, pôde-se observar que a interferência pouco se relaciona com as notificações realizadas no período da amostra. Acredita-se que há falhas no processo de notificação ou as taxas de cobertura vacinal estão sendo tabuladas infielmente. Conclusão: conclui-se que há correlação da cobertura vacinal com as notificações de agravos por sarampo, porém esta acontece de forma indireta, uma vez que necessita não somente dos números notificados como também do meio como são notificados.

Palavras-chave: Sarampo, Cobertura Vacinal, Notificação Compulsória, Vacinação, Programas de Imunização.

\begin{abstract}
Objective: To correlate vaccination coverage with measles reporting numbers in the Federal District from 2008 to 2018. Method: This is a descriptive retrospective study with quantitative analysis using secondary data obtained through the systems of national database, from the period 2008 to 2018, being the Federal District field of study. Results: The results showed that the instability of the Triple Viral VC values in the last decade, with sometimes high, sometimes decayed peaks, and by correlating the data provided by the systems, it was observed that the interference slightly relates to notifications made during the sample period. It is believed that the reporting process is flawed or vaccination coverage rates are being unfaithfully tabulated. Conclusion: it is concluded that there is a correlation between vaccination coverage and measles disease reports, but this happens indirectly, since it requires not only the reported numbers but also the medium as reported.
\end{abstract}

Keywords: Measles, Vaccination Coverage, Compulsory Notification, Immunization, Immunization Programs.

\section{RESUMEN}

Objetivo: correlacionar la cobertura de vacunación con los números de informes de sarampión en el Distrito Federal de 2008 a 2018. Método: Este es un estudio descriptivo retrospectivo con análisis cuantitativo utilizando datos secundarios obtenidos a través de los sistemas de base de datos nacional, desde el período 2008 hasta 2018, siendo el campo de estudio del Distrito Federal. Resultados: Los resultados mostraron que la inestabilidad de los valores de Triple Viral VC en la última década, con picos a veces altos, a veces decaídos, y al correlacionar los datos proporcionados por los sistemas, se observó que la interferencia es leve

${ }^{1}$ Centro Universitário Euro-Americano - UNIEURO. Brasília, Distrito Federal.

2 Universidade de Brasília - UnB. Brasília, Distrito Federal. *E-mail: johnata.matos@unieuro.com.br 
se refiere a las notificaciones realizadas durante el período de muestra. Se cree que el proceso de informe es defectuoso o que las tasas de cobertura de vacunación se tabulan infielmente. Conclusión: se concluye que existe una correlación entre la cobertura de vacunación y los informes de la enfermedad del sarampión, pero esto ocurre indirectamente, ya que requiere no solo los números informados sino también el medio según lo informado.

Palabras-clave: Sarampión, Cobertura Vacunal, Notificación Compulsiva, Vacunación, Programas de Inmunización.

\section{INTRODUÇÃO}

Sarampo define-se como uma patologia infectocontagiosa aguda, grave, mais suscetível em crianças menores de um ano e desnutridas. É causada pelo patógeno, vírus, do gênero Morbillivirus e integrante da família Paramyxovidae (OMS, 2019).

Uma vez infectada, a patologia ocasiona vasculite generalizada na qual traz inúmeras manifestações clínicas, entre elas, a perda de eletrólitos e proteínas, fatores que caracterizam a doença. A infecção dá-se por meio de secreções nasofaríngeas eliminadas no ato de espirrar, tossir e respirar (OPAS, 2019).

O período de incubação do vírus no organismo geralmente é de 10 dias, desde a exposição até o surgimento do exantema, e a transmissibilidade é de 4 a 6 dias antes do surgimento do exantema. A sintomatologia ocorre com o aparecimento de febre $\left(>38,5^{\circ} \mathrm{C}\right)$, acompanhado de tosse produtiva, coriza, conjuntivite e fotofobia, logo após, há o surgimento do exantema (BRASIL, 2009).

O sarampo é uma doença de notificação compulsória imediata, devendo ser realizada em até 24 horas. Conforme a portaria ํㅜㄹ 204/2016 do Ministério da Saúde (MS), a notificação compulsória é uma comunicação obrigatória à autoridade de saúde, de qualquer presunção ou confirmação de danos à saúde pública, podendo ser realizada por profissionais de saúde responsáveis pelas as unidades de saúde pública ou privada (BRASIL, 2016).

Para prevenir o sarampo, foram criadas duas vacinas nomeadas como Tríplice Viral e Tetra Viral que são disponibilizadas pelo Sistema Único de Saúde (SUS). À tríplice é composta de vírus atenuado, com combinação de sarampo, caxumba e rubéola (SRC), é dividida em duas doses (D1 e D2), onde a primeira deve ser administrada em indivíduos com 12 meses de idade e a segunda entre 11 e 49 anos, a depender da situação vacinal, poderá ser aplicada duas doses com intervalo de 30 dias (FIOCRUZ, 2014; BRASIL, 2018a).

No caso da tetra viral, em sua combinação há o acréscimo da varicela com esquema de dose única, que deve ser administrada em indivíduos com 15 meses de idade, seguindo as recomendações do Calendário Nacional de Vacinação da criança (BRASIL, 2013; BRASIL, 2018a).

Com a visão de frear o avanço e eliminar as doenças imunopreveníveis, em 1973, foi instaurado o Programa Nacional de Imunização (PNI) no Brasil, o qual atinge coberturas de 95\% em suas campanhas vacinais, e busca atingir plenamente os princípios da equidade, integralidade e universalidade na atenção à saúde (BRASIL, 2003).

O PNI promoveu o fortalecimento da atribuição do Ministério da Saúde na sistematização e na gestão das operações da vacinação, ofertando vacinação à toda população, no qual que teve um papel essencial na eliminação da poliomielite e do sarampo (SILVA JUNIOR JB, 2013). São realizadas campanhas desde 1995 contra o sarampo, com a vacinação de população alvo específico que, na grande maioria das vezes, abrange as crianças (BRASIL, 2018b).

No que diz respeito à imunização das crianças, vale-se ressaltar o Art. 14 da Lei 8.069/9 do Estatuto da Criança e do Adolescente (ECA), em seu parágrafo único: "É obrigatória à vacinação das crianças nos casos recomendados pelas autoridades sanitárias" (ECA, 1990).

A Organização Mundial da Saúde (OMS) recomenda que para manutenção da erradicação, eliminação ou controle do sarampo, seja alcançado pelo menos 95\% de cobertura vacinal (CV) (OMS, 2019; OPAS, 2019). 
Em 2016, o Brasil obteve certificado de eliminação da circulação do vírus do sarampo concedido pela Organização Pan-Americana da Saúde (OPAS) (BRASIL, 2013), porém, o MS notificou até o dia 12 de dezembro de 2018, 9.779 casos confirmados de sarampo no Amazonas e 349 em Roraima (BRASIL, 2018c).

Um total de 10. 262 casos de sarampo foram confirmados no Brasil, até dezembro de 2018, destes, 45 no Rio Grande do Sul, 19 no Rio de Janeiro, 54 no Pará, 4 em Pernambuco e em Sergipe, 3 em São Paulo, 2 em Rondônia e na Bahia, e apenas 1 no Distrito Federal (DF). Quanto aos óbitos, no mesmo período, foram confirmados 12 óbitos, sendo 4 em Roraima ( 3 em estrangeiros e 1 em brasileiro) e 6 no Amazonas (brasileiros) e 2 no Pará (BRASIL, 2018c).

Evidente a isto, as Sociedades Brasileiras de Pediatria (SBP), de Imunização (SBIm) e de Infectologia (SBI) juntamente com a Rotary Internacional e com o apoio do PNI, assinaram no dia 26 de julho de 2018, em São Paulo, um manifesto que tinha como objetivo, alertar o risco do reaparecimento do Sarampo e da Poliomielite nas Américas e no Brasil (COSTANTINO C, et al., 2018).

Ademais, no manifesto, as sociedades afirmam que as elevadas coberturas vacinais são o necessário para livrar o país das doenças acima citadas, e adverte que a queda da cobertura pode colocar em risco todo o empenho do PNI (COSTANTINO C, et al., 2018).

O MS aponta que a CV é instrumento imprescindível para a escolha de decisão a nível das esferas de governo, pois só com coberturas satisfatórias consegue-se controlar, eliminar ou erradicar doenças imunopreveníveis (BRASIL, 2015).

Diante disso, almeja-se descobrir se a cobertura vacinal afeta diretamente os números de notificação por sarampo. Em face do exposto, o presente estudo tem por objetivo correlacionar a cobertura vacinal com os números de notificação por sarampo no Distrito Federal (DF).

\section{MÉTODOS}

Trata-se de um estudo retrospectivo, descritivo, com análise quantitativa, por meio de dados secundários, obtidos através dos sistemas de base de dados nacionais, do período de 2008 a 2018. O campo de estudo foi o Distrito Federal, que é composto por 31 regiões administrativas, com área territorial de $5.779 .997 \mathrm{Km}^{2}$ (IBGE, 2017), tendo uma população de 2.974 .703 habitantes (IBGE, 2018), de acordo com dados dos últimos censos demográficos, do Instituto Brasileiro de Geografia e Estatística - IBGE.

O período escolhido para estudo foi selecionado por conter maior número de dados informativos relevantes à pesquisa, dando uma visão panorâmica da situação epidemiológica do sarampo ao longo de 10 anos no DF. Usou-se oTabnet@ (Sistema de Informações de Saúde), programa de informações utilizado para a tabulação de dados do Ministério da Saúde e Secretarias Estaduais e Municipais de Saúde, que integra os sistemas de base de dados SIAB (Sistema de Informação da Atenção Básica), SINAN (Sistema de Informação de Agravos de Notificação), DATASUS (Departamento de Informática do Sistema Único de Saúde), sendo possível ter acesso aos números de cobertura vacinal do período estudado. Utilizou-se ainda o IBGE/cidades como fonte de dados demográficos.

Os números de casos notificados e os confirmados por sarampo, foram recolhidos nos boletins epidemiológicos disponibilizados pela Secretaria de Saúde do Distrito Federal (SES-DF). Não foram obtidos valores de notificações referentes ao ano de 2018 nos sistemas de informações e nem nos boletins disponibilizados pela SES-DF. A pesquisa teve tanto número de casos notificados bem como confirmados, e todos os achados foram tabulados pelo programa Excel® 2013 e são apresentados em gráficos.

\section{RESULTADOS}

Na pesquisa realizada, evidenciou-se como resultados, a instabilidade dos valores da CV da Tríplice Viral na última década, com picos ora elevados, ora decaídos. Nota-se ainda, queda significativa da primeira dose (D1) que compõe o esquema de imunização contra o sarampo, nos últimos dois anos. O Gráfico 1 abaixo demonstra toda situação vacinal do DF (Distrito Federal) ao longo de dez anos. 
Gráfico 1 - Cobertura Vacinal em Porcentagem (\%) da Tríplice e Tetra Viral, no DF, de 2008 a 2018.

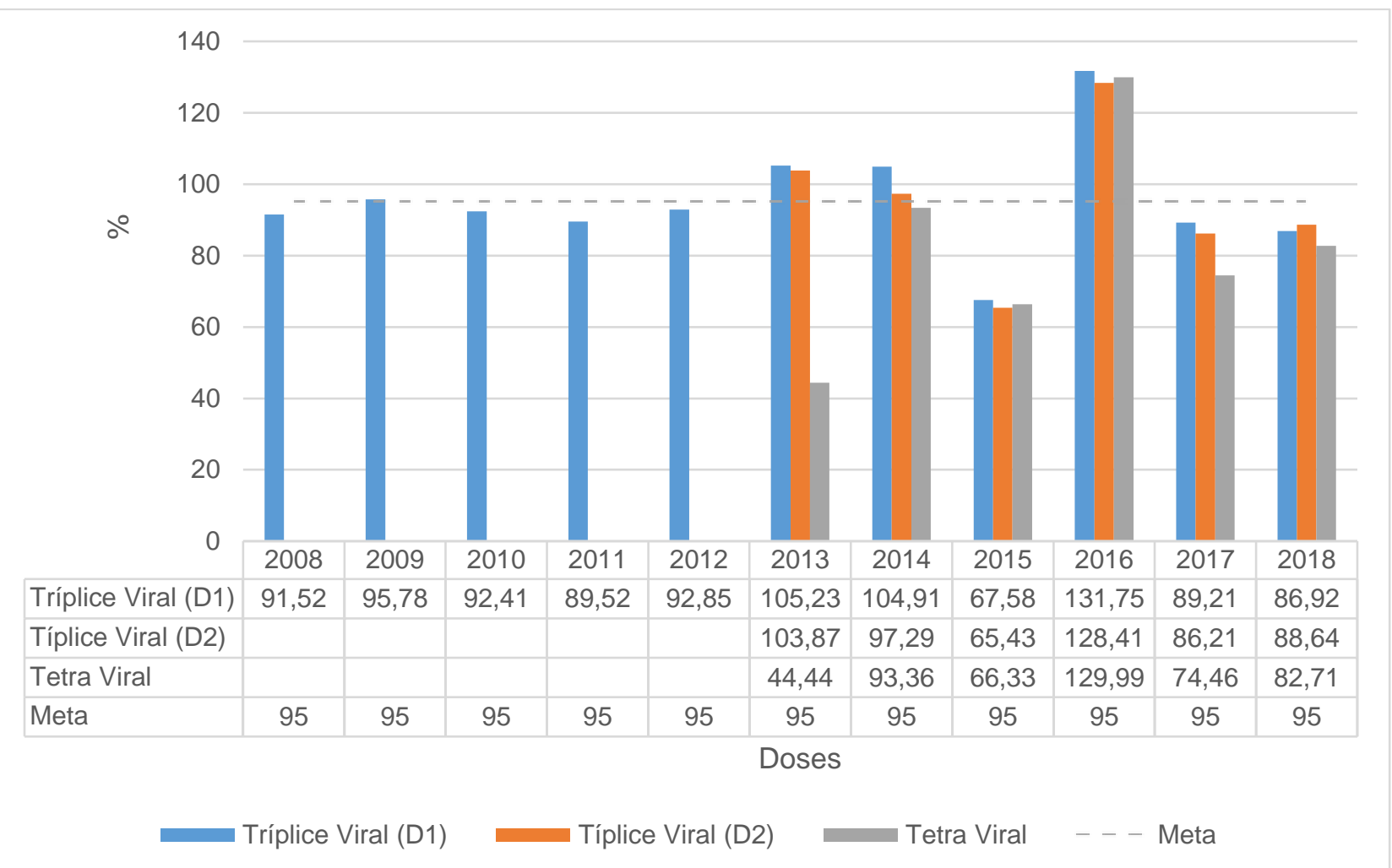

Fonte: Dados do SIS-PNI; TabNet, 2018.

O Gráfico 2 a seguir apresenta todos os casos notificados e confirmados, distribuídos em seus respectivos anos da amostra em estudo, no Distrito Federal.

Gráfico 2 - Número de casos notificados por Sarampo no DF, de 2008 a 2018.

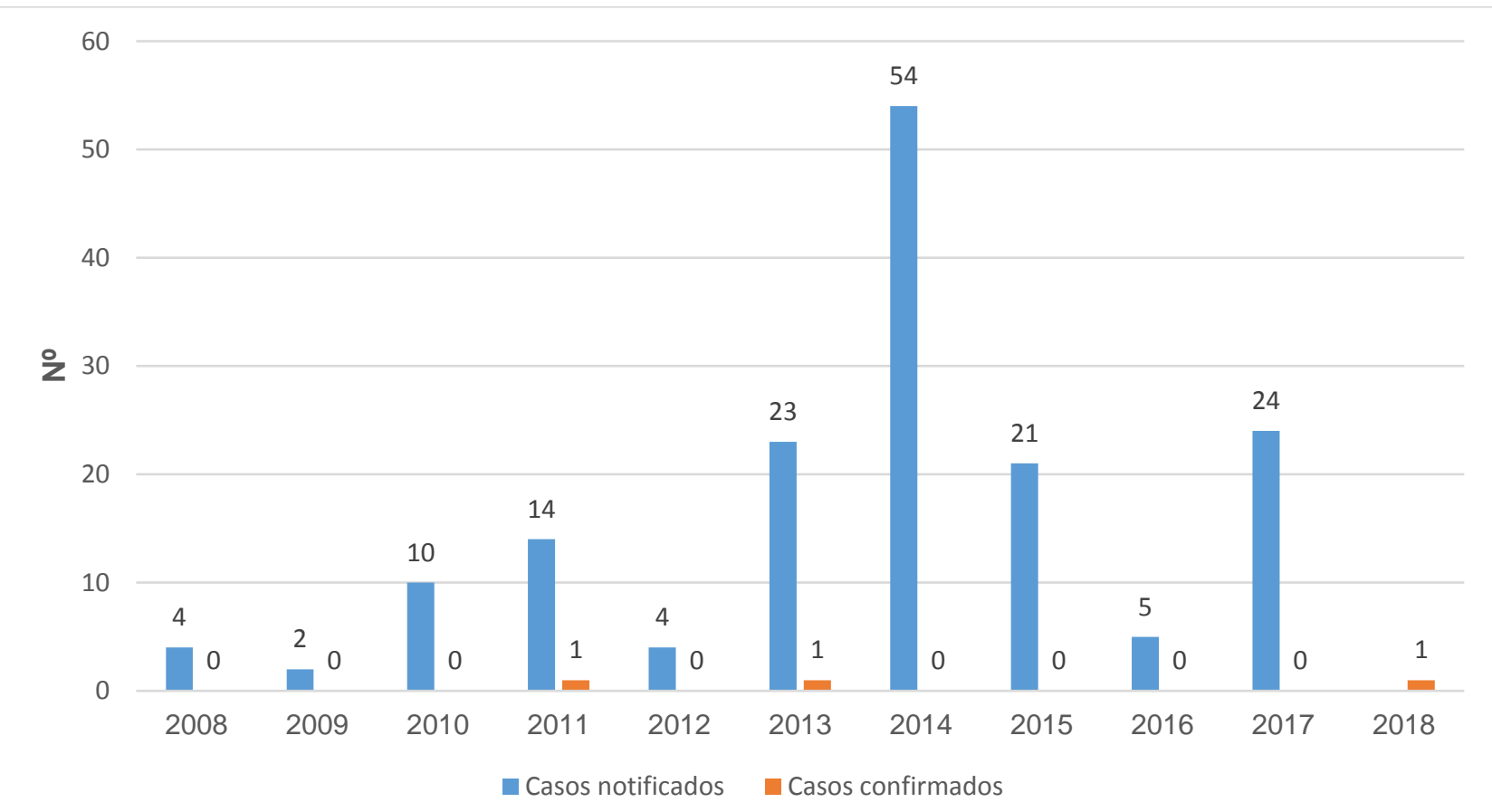

Fonte: Dados da SES-DFe MS, 2018. 
Observa-se que a cobertura da segunda dose (D2) não aparece nos sistemas de informações até 2012, pois foi acrescentada ao calendário vacinal em 2013, juntamente com a Tetra Viral, onde teve início com percentuais bem acentuados, atingindo a meta estabelecida pela OPAS e OMS (95\%) somente nos anos de 2013, 2014 e 2016. No que diz respeito à Tetra Viral, sua cobertura apresentou instabilidade com grande diferença em seus percentuais alcançando meta só no ano de 2016 com cobertura de $130 \%$. Seu menor valor aconteceu em 2013 quando chegou a 44,44\% de cobertura. Os números de casos notificados pela SES-DF no período da amostra, exceto 2018, totalizou 161 casos, destes somente 2 foram confirmados por exames laboratoriais, os demais descartados. Apesar de não encontrado dados de notificações referentes ao ano de 2018, o MS confirma 1 caso no mês de julho do mesmo ano.

Os casos confirmados não foram considerados autóctones, pois segundo a SESDF (DISTRITO FEDERAL, 2017) os ultimos aconteceram no ano de 1999, sendo esses de 2011 e 2013, casos importados de outros paises ou região endêmica.

Acreditava-se que a CV influenciaria nos números notificados com aumento ou diminuição dos seus valores. Ao correlacionar os dados fornecidos pelos sistemas, pôde-se observar que a interferência pouco se relaciona com as notificações realizadas no período da amostra. Segue abaixo, Gráfico 3 panorâmico que correlaciona os casos notificados com os valores de cobertura vacinal do período de estudo.

Gráfico 3 - Correlação da cobertura vacinal com os números de notificações por Sarampo no DF, 2008 2018.

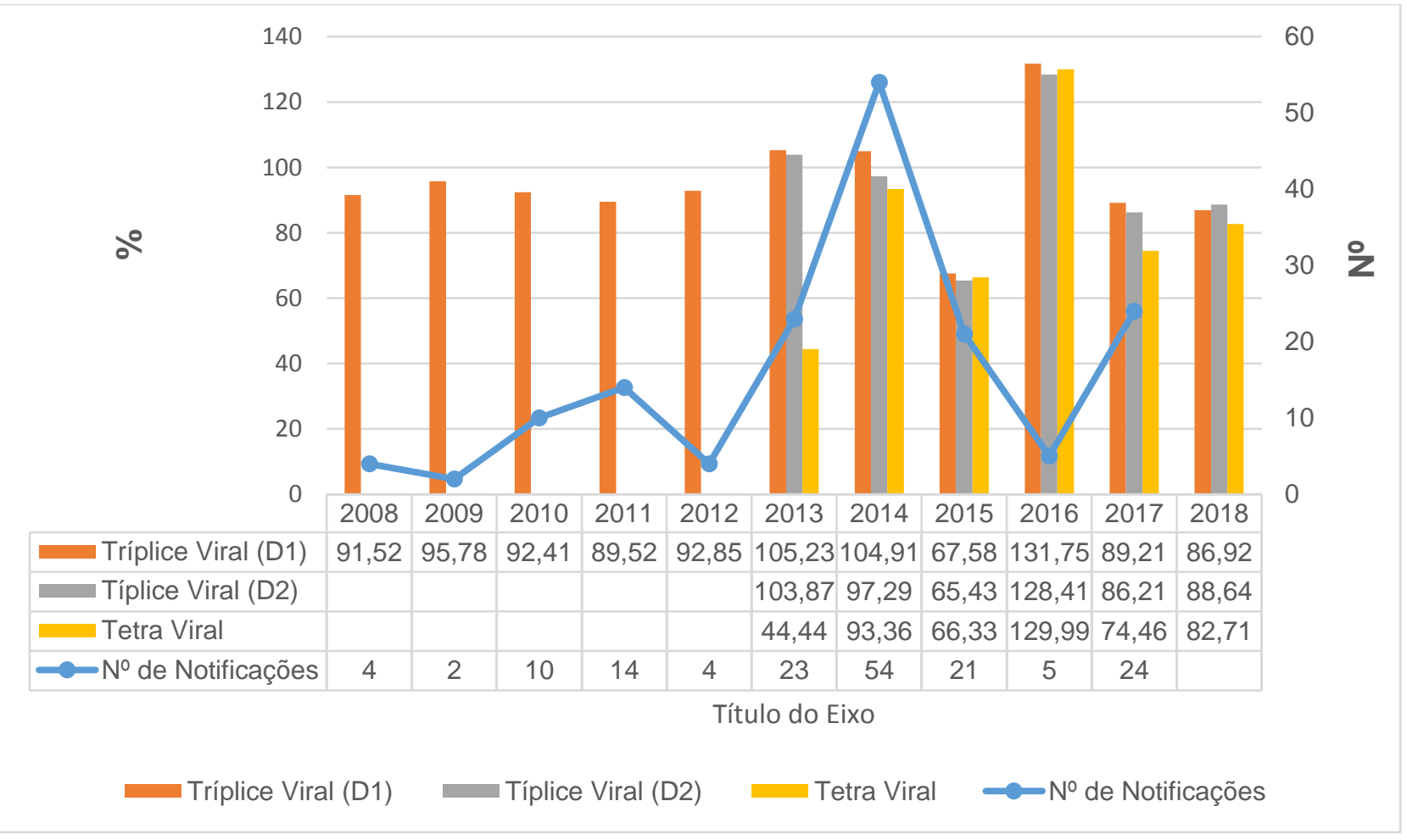

Fonte: Dados do SIS-PNI/SES-DF/MS, 2018.

É possível identificar que nos anos onde não existiam as doses D2 (segunda dose) e Tetra Viral, as notificações eram menores do que nos anos onde existiam as três doses no calendário.

Nota-se que, 2014 foi o ano com maior número notificado (54), porém com uma CV que estava dentro dos valores estabelecidos pelas organizações e MS. Também 2016, que teve maior percentual de coberturas dos últimos dez anos, encontra-se com 1 caso a mais quando comparado com o ano de 2008, que existia unicamente a Tríplice Viral. Mas, ao relacioná-lo com demais anos a partir de 2013, foi o ano com menor número notificado, com CV >128,41\% e nenhum caso confirmado. 
No que tange os casos confirmados, os mesmos aconteceram em 2011, 2013 e 2018. Vale ressaltar que em 2011 não havia D2 e nem a tetra, e seu percentual de cobertura estava abaixo do que é preconizado, ao contrário de 2013 que continha todas as doses do esquema vacinal com coberturas relevantes, porém maior número de notificações. Já em 2018, as coberturas ficaram menores que 95\%.

\section{DISCUSSÃO}

Através dos achados na pesquisa de Braz RM, et al. (2016) compreende-se que a vacinação é o único meio de combate às doenças imunopreveníveis, dentre elas o sarampo, em que uma vez não atingida as metas estabelecidas pela OPAS e OMS (95\%), a população torna-se vulnerável à patologia, o que dificulta o esforço do PNI. Nesse caso, torna-se imprescindível a homogeneidade das CV para controle dessas doenças, em concordância com estudo de Domingues CMAS e Teixeira MAS (2013).

Quando o indivíduo recebe apenas uma dose que compõe o esquema vacinal, tal quantidade pode ser insuficiente para que o sistema imunológico adquira anticorpos de memória e atue em defesa a uma possível infecção, interferindo nas taxas de cobertura aumentando o número de abandono. Ballalaia I e Bravo $F$ (2016) afirmam que o indivíduo só é considerado com esquema vacinal completo quando tiver recebido duas doses após um ano de idade, respeitando o período de 30 dias após a primeira dose. Logo, acredita-se que os casos ocorridos em 2011 e 2018 se deram pelas baixas coberturas, o que torna a população mais suscetível a infecção, e que em 2013 pelo fato de conter 23 casos notificados com 1 confirmados, supõe ter ocorrido falha na tabulação da CV.

A OPAS (2019) preconiza cobertura de $95 \%$ da população. No que tange a vacina tríplice viral e tetra viral, - DF pouco conseguiu chegar a esse desafio, principalmente no ano de 2015, onde as coberturas não passaram de $67,58 \%$. Em 2016, o DF conseguiu atingir meta, homogeneidade e redução de caso, porém houve queda da imunização nos anos seguintes.

Com a queda da CV nos últimos dois anos no DF, a população encontra-se mais suscetível ao sarampo e um fator que corrobora para este risco é o fato da grande circulação de pessoas por meio do turismo, migração e/ou imigração e também eventos de grande massa como ocorrido em 2014, quando o Brasil sediou a copa do mundo (DISTRITO FEDERAL, 2017).

Em um estudo publicado em 2014, o autor já previa a reemergência do sarampo no Brasil por meio do grande número de turistas nas cidades-sedes dos jogos do campeonato mundial, o qual demonstrava as baixas coberturas vacinais da SRC e SRC+V nos anos anteriores a 2014 (MELLO JN, et al., 2014). Nota-se que, 2014 foi o ano com maior número notificado (54), porém com uma CV que estava dentro dos valores estabelecidos pelas organizações e MS.No que diz respeito à queda da imunização, tornam-se notáveis fatores que contribuem para a redução da abrangência da CV, entre eles destaca-se o abandono da continuação do esquema vacinal, evidenciado por motivos ou crenças que não estimulam o usuário a aceitação desse seguimento (BRAZ RM, et al., 2016).

Outro fator contribuinte, é o desconhecimento da importância da vacinação pela população (MIZUTA AH, et al., 2017), o que requer atuação dos profissionais de saúde, na criação de estratégias que contribuam para o ensino-aprendizagem da população, levando informações sobre o processo de imunização, como também orientar sobre efeitos adversos que podem ocorrer com a vacinação e a importância da completude do esquema vacinal.

Quanto a importância de vacinar, vale ressaltar que a escolaridade dos responsáveis, renda, raça, classe social, sexo e número de dependentes são determinantes que contém associação com a CV, em consonância com resultados de autores Silva ATP, et al., (2018) e Yokokura AVCP, et al., (2006).

Estudos afirmam que quanto menor o nível de escolaridade e classe social, maior restrição às informações de promoção e prevenção possui o usuário que se encontra dentro desta classificação. Todavia, o acesso à informação, quando limitado, também influencia na redução da situação vacinal de uma comunidade, visto que o usuário com baixa instrução desconhece a importância da vacinação e da prevenção de agravos por sarampo entre outras patologias (SOUZA FO, ARAÚJO TM, 2016). 
Outrossim, encontra-se o movimento antivacina, cujo motivo da não vacinação são as crenças, o receio da eficácia da vacina e de anafilaxia. Para Silva ATP, et al. (2018), a recusa da vacinação é um desafio para os profissionais da saúde como também para o PNI, em razão da conscientização desta população quanto aos riscos da fragilidade do adoecimento e do combate às enfermidades.

Em caso de recusa da vacinação em crianças por seu responsável legal, independentemente do motivo, exceto anafilaxia, ressalta-se que ele entra em descumprimento com a Lei 8.069/90, que obriga a vacinação das crianças, quando os casos são recomendados pelos sanitaristas (ECA, 1990).

Com relação à anafilaxia, autores afirmam que ocorre quando o sujeito possui alergia a um componente da vacina (BRASIL, 2014; FRANTINATO FFST, et al., 2014). É cabível salientar que em casos de hipersensibilidade ao imunobiológico deve-se realizar uma avaliação direcionada com o fim de identificar o risco-benefício antes da administração.

\section{CONCLUSÃO}

Foi possível, através de levantamento epidemiológico e comparação de dados, alcançar o objetivo de correlacionar as coberturas vacinais com os números de notificações por sarampo no DF. Os resultados do estudo mostraram que não há interferência direta da CV com os números de casos notificados. Logo, conclui-se que a correlação da cobertura vacinal com as notificações de agravos por sarampo acontece de forma indireta, uma vez que necessita não somente dos números notificados como também da forma como são notificados. Evidente a isto, acredita-se que há um possível equívoco na tabulação de dados da cobertura vacinal de anos específicos do período estudado ou no preenchimento das fichas de notificações e a não realização desta nos anos em que inexistia a obrigatoriedade da notificação compulsória.

\section{REFERÊNCIAS}

1. BALLALAIA I, BRAVO F. Imunização: tudo que você sempre quis saber. 3. ed. Rio de Janeiro: RMCOM, 2016.

2. BRASIL. Casa Civil. Lei no 8.069 , de 13 de julho de 1990. Dispõe sobre o Estatuto da Criança e do Adolescente e dá outras providências. Presidência da República do Brasil, Brasília (DF), 1990.

3. BRASIL. Ministério da Saúde. Calendário Nacional de Vacinação 2018. Brasília: Ministério da Saúde; $2018 a$.

4. BRASIL. Ministério da Saúde. Manual de Vigilância Epidemiológica de Eventos Adversos Pós-Vacinação. 3. ed. Brasília: Ministério da Saúde; 2014.

5. BRASIL. Ministério da Saúde. Portaria № 204, de 17 de fevereiro de 2016. Define a Lista Nacional de Notificação Compulsória de doenças, agravos e eventos de saúde pública nos serviços de saúde públicos e privados em todo o território nacional, nos termos do anexo, e dá outras providências. Diário Oficial da União Brasil, Brasília (DF), 2016.

6. BRASIL. Ministério da Saúde. Secretaria de Vigilância em Saúde. Departamento de Vigilância Epidemiológica. Coordenação-Geral do Programa Nacional de Imunizações. Informe Técnico de Introdução da Vacina Tetra Viral. Vacina sarampo, caxumba, rubéola e varicela. Brasília: Ministério da Saúde; 2013.

7. BRASIL. Ministério da Saúde. Secretaria de vigilância em saúde. Departamento de vigilância epidemiológico. Informe Técnico Campanha Nacional de Vacinação Contra a Poliomielite e Contra o Sarampo. Brasília: Ministério da Saúde; 2018b.

8. BRASIL. Ministério da Saúde. Secretaria de Vigilância em Saúde. Programa Nacional de Imunização. Coberturas vacinais no Brasil, 2010 a 2014. Brasília: Ministério da Saúde; 2015 out.

9. BRASIL. Ministério da Saúde. Secretaria de Vigilância Epidemiológica. Departamento de Vigilância Epidemiológica. Guia de Vigilância Epidemiológica. 7. ed. Brasília: Ministério da Saúde; 2009.

10. BRASIL. Portal Ministério da Saúde. Ministério atualiza casos de sarampo. 2018c.

11. BRASIL. Secretaria de Vigilância em Saúde. Programa Nacional de Imunização 30 anos. Série C. Projetos e Programas e Relatórios. Brasília: Ministério da Saúde; 2003.

12. BRAZ RM, et al. Classificação de riscos de transmissão de doenças imunopreveníveis a partir de indicadores de coberturas vacinais nos municípios brasileiros. Epidemiol. Serv. Saude. 2016 out-dez [citado 2019 jun 26]; 25(4): 745-754.

13. CONSTANTINO C, et al. Manifesto SBIm, SBI, SBP e Rotary Internacional. São Paulo, 2018.

14. DISTRITO FEDERAL. Subsecretaria de Vigilância à Saúde. Informativo epidemiológico das doenças imunopreveníveis de transmissão respiratória no Distrito Federal. Distrito Federal: Subsecretaria de Vigilância à Saúde; 2017.

15. DOMINGUES CMAS, TEIXEIRA AMS. Coberturas vacinais e doenças imunopreveníveis no Brasil no período $1982-$ 2012: avanços e desafios do Programa Nacional de Imunizações. Epidemiol. Serv. Saúde. 2013 mar; 22(1): 9-27.

16. FIOCRUZ. Vacina Tríplice Viral. 2014. 
17. FRANTINATO FFST et al. Anafilaxia relacionada à vacina sarampo, caxumba e rubéola, Santa Catarina, Brasil, 2014 e 2015. Cad. Saúde Pública. 2018 mar; 34(3): 1-9.

18. Instituto Brasileiro de Geografia e Estatística (IBGE). Censo demográfico: área territorial. Brasília; 2017.

19. Instituto Brasileiro de Geografia e Estatística (IBGE). Censo demográfico: população estimada. Brasília; 2018.

20. MELLO JN, et al. Panorama atual do sarampo no mundo risco de surtos nos grandes eventos no Brasil. JBM. 2014 jan/fev; 102(1): 33-40.

21. MIZUTA AH, et al. Percepção da importância das vacinas e da recusa vacinal numa escola de medicina. Rev Paul Pediatr. 2017 jul; 37(1): 34-40.

22. ORGANIZAÇẪO DAS NAÇÕES UNIDAS. Sarampo. Genebra. 2019.

23. Organização Pan-americana da Saúde - OPAS. Sarampo, folha informativa. Brasília. 2019.

24. SILVA ATP, et al. Cumprimento do esquema vacinal em crianças internadas por pneumonia e fatores associados. Rev Saude Publica. 2018; 52(38): 1-10.

25. SILVA JUNIOR JB. 40 anos do Programa Nacional de Imunizações: uma conquista da Saúde Pública brasileira. Epidemil Serv Saude. 2013 mar; 22(1).

26. SOUZA FO, ARAÚJO TM. Perfil vacinal dos trabalhadores do setor saúde da bahia. Rev. Saúde Col. 2016 jun; 6(1): 1-7.

27. YOKOKURA AVCP, et al. Cobertura vacinal e fatores associados ao esquema vacinal básico incompleto aos 12 meses de idade, São Luís, Maranhão, Brasil, 2006. Cad Saúde Pública. 2013 mar; 29(3):522-34. 